\title{
Transcriptomic analysis of reproductive damage in the epididymis of male Kunming mice induced by chronic infection of Toxoplasma gondii PRU strain
}

\author{
Yu-Xiang Zheng ${ }^{1,2+}$, Xiu-Xiang Zhang ${ }^{3 \dagger}$, Jorge A. Hernandez ${ }^{4}$, Yasser S. Mahmmod ${ }^{5,6}$, Wan-Yi Huang ${ }^{1,2}$, \\ Gui-Feng Li ${ }^{1,2}$, Ya-Pei Wang ${ }^{1,2}$, Xue Zhou ${ }^{1,2}$, Xiu-Ming Li ${ }^{7^{*}}$ and Zi-Guo Yuan ${ }^{1,2^{*}}$
}

\begin{abstract}
Background: Some researchers have reported that Toxoplasma gondii can cause serious reproductive impairment in male animals. Specifically, T. gondii destroy the quality of sperm in the epididymis, which affects their sexual ability. However, among such studies, none have investigated the male reproductive transcriptome. Therefore, to investigate the relationship between T. gondii and sperm maturation, we infected mice with T. gondii prugniaud (PRU) strain and performed transcriptome sequencing of the epididymis.

Results: Compared with the control group, 431 upregulated and 229 downregulated differentially expressed genes (DEGs) were found ( $P$-value $<0.05$, false discovery rate (FDR) $<0.05$ and $\mid \log 2$ (fold change) $\geq 1$ ). According to results of a bioinformatics analysis, Gene Ontology (GO) function is divided into three categories: cellular component, molecular function and biological process. Upon performing GO analysis, we found that some DEGs correlated with an integral part of membrane, protein complex, cell surface, ATP binding, immune system process, signal transduction and metabolic process which are responsible for the epididymal injury. DEGs were mapped to 101 unique KEGG pathways. Pathways such as cytokine-cytokine receptor interaction, glycolysis/gluconeogenesis and apoptosis are closely related to sperm quality. Moreover, Tnfsf10 and spata18 can damage the mitochondria in sperm, which decreases sperm motility and morphology.

Conclusions: We sequenced the reproductive system of male mice chronically infected with T. gondii, which provides a new direction for research into male sterility caused by Toxoplasma infection. This work provides valuable information and a comprehensive database for future studies of the interaction between T. gondii infection and the male reproductive system.
\end{abstract}

Keywords: Toxoplasma gondii, Chronic infection, Reproductive impairment, DEGs, RNA-seq

\section{Background}

Toxoplasma gondii is an intracellular parasite that infects almost all warm-blooded animals [1, 2]. Pregnant women infected with $T$. gondii can transmit the

\footnotetext{
*Correspondence: Ixm_nj@qq.com; ziguoyuan@scau.edu.cn

${ }^{\dagger}$ Yu-Xiang Zheng and Xiu-Xiang Zhang contributed equally to this work

${ }^{1}$ College of Veterinary Medicine, South China Agricultural University,

Guangzhou 510642, Guangdong, People's Republic of China

${ }^{7}$ College of Animal Science and Technology, Heilongjiang BaYi

Agricultural University, Daqing 163319, People's Republic of China

Full list of author information is available at the end of the article
}

infection to their fetus through vertical transmission resulting in abortion, fetal abnormalities and death [3]. Additionally, Toxoplasma infection can cause damage to the male reproductive system, such as sexual dysfunction and infertility. The epididymis is an important accessory organ of the male reproductive system, where sperm maturation and storage take place. Sperm maturation in the epididymis is a highly programmed process which may be affected by the epididymis microenvironment. Therefore, studying the characteristics of 
the epididymis is important for identification of factors affecting sperm maturation. Previous studies have shown that reproductive pipeline damage [4] and hypogonadism [5] are associated with $T$. gondii infection. Furthermore, a large number of tachyzoites in semen of infertile patients and anti-sperm antibodies (AsAb) were detected in $T$. gondii infection [6]. Other studies have reported more advanced pathological changes in T. gondii infection cases, such as granular degeneration of vas deferens epithelial cells, luminal stenosis and interstitium infiltration with inflammatory cells [7]. The density and motility rate of sperm in epididymis infected with $T$. gondii were significantly lower than the control group; however, the rate of sperm deformity was increased $[8,9]$.

Recently, various -omics technologies, including transcriptomics, proteomics and metabolomics, have been developed [10]. Transcriptomic analysis is one of the most common high-throughput techniques, which identify the types and copy numbers of mRNAs, while the cells are living in a functional state [11]. Genetic studies have shown that mRNA act as a "bridge" for genetic information transmission between DNA and protein. Hence, it is a valuable source to identify the expression of all genes with a specific time and space in the cell.

Previous studies have investigated the association between $T$. gondii and male infertility using epidemiology, pathology and serology methods and techniques [12], detection of Toxoplasma DNA in semen [13] and observation of the tissue and cell damage [14]. To our knowledge, studies investigating the differentially expressed genes of host and T. gondii by transcriptome sequencing of the male reproductive system are limited. The main objective of this study was to examine differential gene expression by RNA sequencing (RNA-seq) technology in order to identify key genes associated with $T$. gondii (PRU strain) chronic infection of the epididymis in male Kunming mice.

\section{Methods}

\section{Study population and experiment set-up}

Thirty specific-pathogen-free eight-week-old Kunming male mice were purchased from the Laboratory Animal Center of Guangdong Province. Fifteen mice were subjected as the experiment groups, and 15 mice were subjected as the control group (to reduce individual differences, we set the epididymal tissue of 5 mice as a biological replicate, the experiment group and the control group were repeated three times). Mice in the experimental group were inoculated with four cysts of $T$. gondii PRU strain diluted with normal saline to $0.5 \mathrm{ml}$ through the intragastric administration route (we have previously studied the optimal number of PRU strains infections per mice, which tried to minimize the case damage caused by $T$. gondii infection in mice). Meanwhile, the control groups were given the same amount of normal saline only. The male mice were sacrificed at 35 days post-infection. Under sterile conditions, the epididymides were harvested. Under the microscope, the peripheral adipose tissue and blood vessels of the harvested epididymides were carefully removed. The processed epididymides were subjected to quick freezing by storing them in liquid nitrogen at $-80^{\circ} \mathrm{C}$ for subsequent analysis.

\section{Transcriptome sequencing, data analysis and verification} At present, transcriptome sequencing is a mature highthroughput second-generation sequencing method. A brief description of the experimental process is provided in Table 1; detailed methods of transcriptome sequencing, data analysis and verification can be found in Additional file 1: Text S1.

\section{Results}

\section{Pre-experiment}

Before the histological analysis, we conducted a preliminary study on the sperm quality of $T$. gondii infection, including the statistics of sperm survival rate

Table 1 Procedures for transcriptome sequencing, data analysis and validation

\begin{tabular}{|c|c|}
\hline Experimental procedure & Experimental method or threshold considered \\
\hline Extraction of total RNA & Trizol reagent (Invitrogen, CA, USA) \\
\hline Quality and purity detection of total RNA & RNA 6000 Nano LabChip Kit (Agilent, CA, USA) with RIN number $>7.0$ \\
\hline cDNA library construction & $\begin{array}{l}\text { The cleaved mRNA fragments were reverse-transcribed to create the final cDNA library by the instruc- } \\
\text { tions of the mRNA-Seq sample preparation kit (Illumina, San Diego, USA) }\end{array}$ \\
\hline Sample library construction & Illumina Hiseq 2500 sequencing platform \\
\hline Transcript abundance estimation & $\begin{array}{l}\text { The RPKM of each gene were calculated by the MARS model in DEGseq program, when the RPKM } \\
\text { greater than 1000, it is considered to be a highly expressed gene }\end{array}$ \\
\hline Threshold of differentially expressed genes & FDR (false discovery rate) $<0.001$ and $\mid \log 2$ fold change $\mid \geq 1$ \\
\hline Bioinformatics analysis & GO and KEGG enrichment \\
\hline Verification of mRNA expression level & Real-time fluorescence quantitative PCR \\
\hline Verification of protein expression level & Western blot \\
\hline
\end{tabular}


and total sperm count. The sperm survival rate was calculated according to the formula: Sperm survival rate $=($ Total sperm count - Dead sperm count $) /$ Total sperm count $\times 100 \%$; three experiments were carried out in each group. The results showed that the sperm survival rate of the experimental group (32\%) was significantly lower than that of the control group (74.67\%).

The sperm count per milliliter semen was calculated according to the formula: Sperm count per milliliter semen $=(5$ medium square count $/ 80) \times 400 \times$ dilution multiple $\times 10,000$. We diluted sperm 10 times for microscopic examination. The experimental data are shown in Additional file 2: Figure S1; there were significant differences in total sperm count between the experimental group and the control group $(P=0.0058)$. The data showed that T. gondii infection had a negative effect on sperm quality.

\section{Identification of infection in mice}

The outward appearance changes of infected mice comprised mainly a stress reaction about a week after infection, which included depression and the fur is not smooth. Thirty days after infection, 20 mice were selected for tail vein blood collection and qPCR was used to verify the infection of mice (T. gondii ROP18 virulence gene was detected and using the $\beta$-actin as a reference); the result is shown in Additional file 3: Figure S2. All of the 20 mice were infected. Fifteen mice were randomly selected for dissection and epididymis tissue was quickly removed. Meanwhile, the mouse brain was grinded and diluted with $100 \mu$ saline solution; $5 \mu \mathrm{l}$ of brain homogenate was taken for microscopic examination and the number of cysts was counted. Cysts from each mouse were counted three times and averaged. Statistical results showed that $5 \mu \mathrm{l}$ brain homogenate contained three or more cysts. Therefore, we determined that all of the experimental mice were infected with $T$. gondii.

\section{Quality analysis of RNA}

The purity of total RNA was high, and the ratios $\mathrm{OD}_{260} /$ $\mathrm{OD}_{280}$ and $\mathrm{OD}_{260} / \mathrm{OD}_{230}$ were both higher than 2.0 (Table 2). The RNA integrity number (RIN) was higher than 7 , and the ratio of $28 S / 18 S$ rRNA was higher than 0.7. This indicated that the RNA had good integrity and met the requirements of the subsequent experiments.

\section{Sequencing data preprocessing}

The sample library constructed by Illumina Hiseq 2500 sequencing platform. We obtained $321,183,388$ raw reads (48.17G). After trimming, we obtained 314,632,244 clean reads (47.21G). Among them, the amounts of sequencing data of each sample were more than 6G. In high throughput sequencing, each measurement of a basic group gives a corresponding value, which is a measure of the accuracy (Table 3 ).

\section{Analysis of gene expression}

RPKM/FPKM was used to measure the abundance of gene expression in the transcriptome. We used FPKM to estimate the abundance of known genes expresses in different samples. After the construction of new transcripts, 69,907 transcripts and 29,128 unigenes were obtained.

Table 2 Quality analysis of RNA

\begin{tabular}{|c|c|c|c|c|c|c|c|}
\hline Sample & Concentration $(\mu \mathrm{g} / \mu \mathrm{l})$ & O.D. $260 / 280$ & O.D. $260 / 230$ & Amount $(\mu \mathrm{g})$ & $\begin{array}{l}\text { rRNA } \\
28 S / 18 S\end{array}$ & RIN & QC evaluation \\
\hline PRU-1 & 1.46 & 2.07 & 2.3 & 65.83 & 0.8 & 7 & A \\
\hline PRU-2 & 1.16 & 2.09 & 2.25 & 52.24 & 1.8 & 7.2 & A \\
\hline$P R U-3$ & 1.38 & 2.08 & 2.28 & 62.34 & 1.5 & 7.5 & A \\
\hline Control-1 & 0.87 & 2.07 & 2.35 & 39.35 & 0.8 & 7 & A \\
\hline Control-2 & 1.69 & 2.1 & 2.32 & 76.25 & 1.7 & 7.9 & A \\
\hline Control-3 & 1.26 & 2.03 & 2.29 & 56.65 & 1.8 & 8.1 & A \\
\hline
\end{tabular}

Table 3 Pre-treatment results of data quality in the high throughput sequencing

\begin{tabular}{|c|c|c|c|c|c|c|c|c|}
\hline Sample & Raw data reads & Base & Valid data reads & Base & Valid reads \% & Q20\% & Q30\% & GC\% \\
\hline PRU-1 & $42,640,370$ & $6.4 \mathrm{G}$ & $41,484,632$ & $6.22 \mathrm{G}$ & 97.29 & 98.77 & 90.81 & 46.5 \\
\hline PRU-2 & $49,368,291$ & $7.4 \mathrm{G}$ & $48,326,910$ & $7.25 \mathrm{G}$ & 97.89 & 98.47 & 90.93 & 48.0 \\
\hline PRU-3 & $43,890,326$ & $6.58 \mathrm{G}$ & $42,897,451$ & $6.44 \mathrm{G}$ & 97.74 & 98.93 & 90.25 & 47.7 \\
\hline Control-1 & $62,208,188$ & $9.33 G$ & $60,729,140$ & $9.11 \mathrm{G}$ & 97.62 & 98.86 & 91.00 & 47.5 \\
\hline Control-2 & $58,037,289$ & $8.7 \mathrm{G}$ & $57,291,719$ & $8.6 \mathrm{G}$ & 98.71 & 98.72 & 90.35 & 50.0 \\
\hline Control-3 & $65,038,924$ & $9.76 \mathrm{G}$ & $63,902,392$ & $9.59 \mathrm{G}$ & 98.25 & 99.04 & 91.37 & 46.5 \\
\hline
\end{tabular}

Notes: Q20\%, error rate is $1 \%$, or the correct rate is $99 \%$; Q30\%, error rate is $0.1 \%$, or the correct rate is $99.9 \%$ 
The five-demographic data (distribution) of experimental and control groups are shown in Fig. 1.

\section{Analysis of DEGs}

Significant DEGs from the differential genes with $P<0.05, \mid \log 2$ (fold change) $\mid \geq 1$ and the FDR corrected $P$-value $<0.05$ were selected. The overall distribution of DEGs was observed by drawing a volcano plot (Fig. 2). Compared with the control group, the number of up- and downregulated genes was 431 and 229, respectively. Partial DEGs are listed in Tables 4 and 5.

\section{Bioinformatics analysis for the DEGs}

GO database analysis was conducted on the DEGs, including biological processes (1746), cellular components (1275) and molecular functions (785); the distribution diagram of GO terms with significant changes



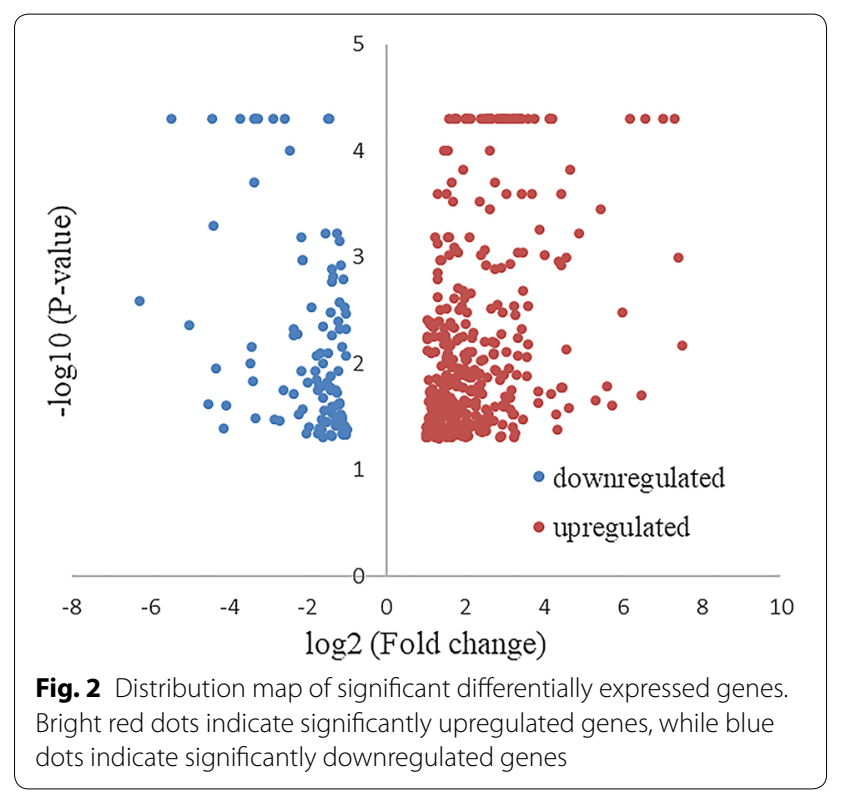

in classification is shown in Fig. 3. The main categories in the biological processes include immune system process, response to stress and signal transduction. As for the cellular components, the GO terms with the most differentially expressed genes were cell, intracellular and organelle. The molecular functions were involved mainly in the protein binding followed by ion binding, and transmembrane transporter activity.

KEGG database analysis showed that the DEGs were enriched in 101 pathways. The most enriched pathways of DEGs are exhibited in Fig. 4. Markedly, cell adhesion (31), phagosome (27) and natural killer cell mediated cytotoxicity (17) were the major three enriched pathways (Fig. 4). However, the pathway directly related to male reproduction was not found.

\section{Verification results by qPCR analyzing and western blotting}

The eight genes related to reproduction were identified by qPCR (Table 6); these expression trends were coincident with RNA-seq results (Fig. 5). The result of qPCR did not coincide with the RNA-seq perfectly; however, it is still possible to increase the reliability of these genes to a certain extent. DEGs including Piwil2, Spata18 and Tnfsf10 were selected for Western blot analysis. The results of the Western blot showed the same changing trend as the results of RNA-seq, although the specific amount of expression was different (Fig. 6).

\section{Discussion}

We investigated the pathogenesis of $T$. gondii in the male reproductive tract of mice at the stage of sperm maturation using RNA-Seq technology. Additionally, 
Table 4 Partial of upregulated DEGs in the high throughput sequencing data

\begin{tabular}{|c|c|c|c|}
\hline Symbol & Name & $\log 2(F C)$ & Function \\
\hline ligp1 & Interferon-inducible GTPase 1 & 6.5608 & $\begin{array}{l}\text { Required for disruption of the parasitophorous vacuole formed following } \\
\text { T. gondii infection and subsequent killing of the parasite }\end{array}$ \\
\hline Klrb1c & Killer cell lectin-like receptor subfamily B member $1 C$ & 6.17868 & $\begin{array}{l}\text { Plays a stimulatory role on natural killer (NK) cells cytotoxicity, activa- } \\
\text { tion by cross-linking of the receptor induces } \mathrm{Ca}^{2+} \text { mobilization and } \\
\text { interferon-gamma production }\end{array}$ \\
\hline Tgtp1 & T cell-specific GTPase 1 & 5.61362 & $\begin{array}{l}\text { Involved in innate cell-autonomous resistance to intracellular pathogens, } \\
\text { such as T. gondii }\end{array}$ \\
\hline Tnfsf10 & Tumor necrosis factor (ligand) superfamily, member 10 & 1.53097 & $\begin{array}{l}\text { Involved in male gonad development and regulation of the apoptotic } \\
\text { process }\end{array}$ \\
\hline Spata18 & Spermatogenesis associated 18 & 1.29567 & $\begin{array}{l}\text { A key regulator of mitochondrial quality that mediates the repairing or } \\
\text { degradation of unhealthy mitochondria in response to mitochondrial } \\
\text { damage }\end{array}$ \\
\hline Pgk2 & Phosphoglycerate kinase 2 & 1.11099 & $\begin{array}{l}\text { Essential for sperm motility and male fertility but is not required for the } \\
\text { completion of spermatogenesis }\end{array}$ \\
\hline Piwil2 & Piwi-like RNA-mediated gene silencing 2 & 1.1907 & $\begin{array}{l}\text { Essential role in meiotic differentiation of spermatocytes and self-renewal } \\
\text { of spermatogonial stem cells }\end{array}$ \\
\hline
\end{tabular}

Table 5 Partial of downregulated DEGs in the high throughput sequencing data

\begin{tabular}{|c|c|c|c|}
\hline Symbol & Name & $\log 2(F C)$ & Function \\
\hline Lipf & Gastric triacylglycerol lipase & -3.40022 & $\begin{array}{l}\text { Involved in lipid catabolic process and mitochondria when classification of } \\
\text { cellular component }\end{array}$ \\
\hline Nrk & Nik-related protein kinase & -3.41519 & Involved in the TNF-alpha-induced signaling pathway \\
\hline Nwd1 & NACHT and WD repeat domain containing 1 & -1.60721 & $\begin{array}{l}\text { Play a role in the control of androgen receptor (AR) protein steady-state } \\
\text { levels }\end{array}$ \\
\hline Slc14a2 & Solute carrier family 14 (urea transporter), member 2 & -1.11457 & $\begin{array}{l}\text { Mediates rapid transepithelial urea transport across the inner medullary } \\
\text { collecting duct and plays a major role in the urinary concentrating } \\
\text { mechanism }\end{array}$ \\
\hline Spink2 & Serine protease inhibitor Kazal type 2 & -1.02159 & $\begin{array}{l}\text { Required for maintenance of normal spermatogenesis, involved in regulat- } \\
\text { ing serine protease-dependent germ cell apoptosis }\end{array}$ \\
\hline
\end{tabular}

we performed enrichment methodologies analysis to screen the DEGs that might be related to the reproductive functions. Results were confirmed by using qPCR and Western blot methods. Our findings showed that the RNA-Seq is accurate.

The analysis of DEGs suggested that some genes were interrelated with the infection of T. gondii, such as Iigp1 (interferon-inducible GTPase 1), Tgtp1 (T-cell-specific guanine nucleotide triphosphate-binding protein 1) and Tgtp2. Iigp1 found in the parasitophorous vacuoles (PV) plays a role in the destruction of PV and death of the parasite, when the Iigp1 gene is overexpressed [15]. We found that Iigp1 was in regulation of autophagy in the GO classification. Hence, it is possible that Iigp1 is involved in autophagy, although the specific mechanism is not clear. During infection of the type II of T. gondii, Tgtp 1 and Tgtp 2 were recruited to the PV membrane, PV vesiculation, rupture and digestion of the parasite within the cytosol $[15,16]$. In our study, the Iigp1, Tgtp1 and Tgtp 2 were significantly upregulated by 94 -fold, 48 -fold and 23 -fold, respectively. This could be the result of host resistance to $T$. gondii. However, after $T$. gondii infection, Tgtp1 and Tgtp2 had low levels of gene expression abundance. The average abundance of $\operatorname{Tgtp} 1$ was 13.7 for the experimental group and 0.58 for the control group and the average abundances of Tgtp 2 were 15.39 and 0.31 , respectively. $\operatorname{Tgt} p 1$ and $\operatorname{Tgtp} 2$ are mainly expressed in the thymus and lymph nodes, predominantly T-cells and IFNG-stimulated macrophages [17]. In other words, these genes are tissue-specific. After T. gondii infection, the immune system was stimulated, and the expression level of these genes was greatly increased.

\section{Glycolytic pathway and sperm motility}

There are several enriched pathways in our data analysis. Glycolysis was thought to be the oldest and most primitive way of biological energy harvesting. We focused on DEGs that affect glycolysis such as phosphoglycerate kinase 2 (Pgk2), phosphoglycerate mutase (Pgam) and lactate dehydrogenase $\mathrm{C}(\mathrm{LDHC})$. Phosphoglycerate kinase is the first regulation factor of ATP generated in the glycolysis pathway. In the reproductive system, the 



Fig. 4 The most enriched pathways of DEGs

examination of sperm in elderly and young male patients with asthenospermia showed that the level of Pgk2 was reduced. $P g k 2$, which is related to the quality of sperm, is mainly expressed in able-bodied spermatids [18]. $P g k 2$ deficiency leads to a decrease in sperm motility and ATP levels [19]. Pgam is an important enzyme of glycolysis and gluconeogenesis pathway, catalyzes the 3-phosphoglycerate (3-PGA) into 2-phosphoglycerate (2-PGA), which dominates the balance between glycolysis and gluconeogenesis. Moreover, Pgam2 is related to the fibrous sheath of the main segment in the sperm flagellum [20]. The fibrous sheath on the sperm flagellum is the source of ATP and an essential structure of sperm motility [21]. Therefore, Pgam2 is the key determinant to maintaining sperm motility and morphology. $L D H C$ is an enzyme that controls the conversion of pyruvate to L-lactic acid, which plays a key role in the process of spermatogenesis and capacitation by participating in cellular 
Table 6 Design of primers used for qPCR analysis

\begin{tabular}{lllll}
\hline Gene ID & Gene & Forward primer & Reverse primer & Product length (bp) \\
\hline 57746 & piwil2 & GGCAGAGGCCTTGTGTTTAG & CGTTTTGAAGGAGGCCGGAA & 134 \\
73472 & Spata18 & TTATCACGTGTGGCCTGCTC & TTAAGCTCCTGCTACGGCAC & 125 \\
22035 & Tnfsf10 & ACGCTTCCAAGATGGTCTCA & ACAGTCCGTACTCGGCATCT & 147 \\
21822 & Tgtp1 & CGCCACGTCTTCTCACTGTC & CACCAAGTGGAATGGTGGCT & 130 \\
60440 & ligp1 & TCACTATGACTTCCCCTCCT & TGCTTCAGAAATTGCCGCTT & 132 \\
18663 & Pgk2 & GCCTGTGCCAACCCAGATAA & ACAGTGATGCTTGGAAGGCT & 145 \\
319555 & Nwd1 & CTCTTGGACCACCAGGCAT & AGGCTCAGCTTTGATGTCCC & 125 \\
69982 & Spink2 & GCATGCCCTAGGACCTCAA & ATATGGCTACCGTCCTCCCT & 101 \\
11461 & B-actin & AGAGAAGCTGTGCTATGTTGCT & GGAACCGCTCGTTGCCAATA & 128 \\
\hline
\end{tabular}

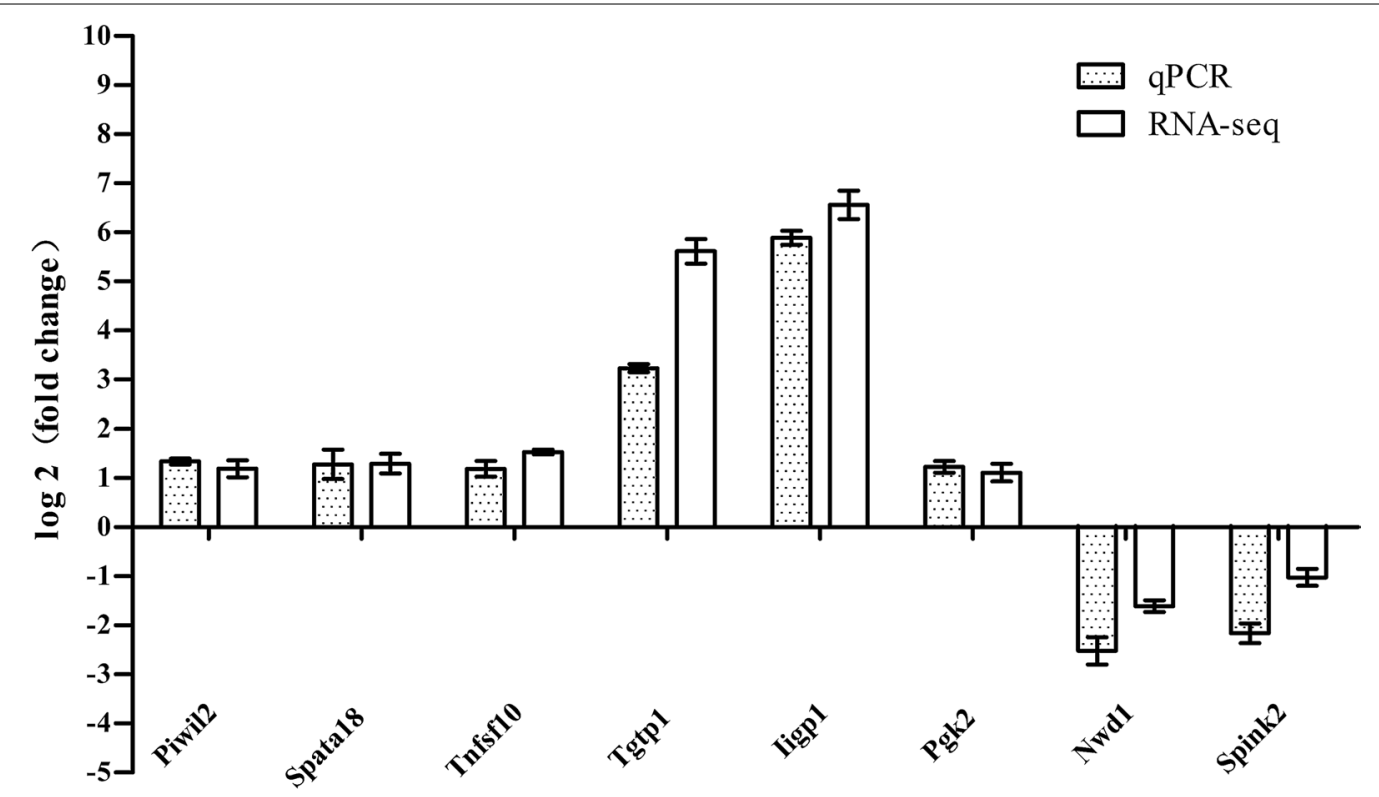

Fig. 5 Results of qPCR and compared with RNA-seq

energy metabolism [22]. $L D H C$ was found in the human spermatozoa and spermatogenic cells and was increased gradually with meiosis. $L D H C$ in mature sperm is mainly located in the fibrous sheath of the main segment of the tail of sperm, which is involved in the regulation of sperm motility. In addition, $L D H C$ is also participates in the homeostasis of ATP. Deficiency/destruction of germlinespecific $L D H C$ leads to infertility, including a reduction in sperm ATP content and reduced sperm motility [22, 23]. Conclusively, the enzymes are closely linked with sperm activity and morphology.

In the present study, the DEGs of glycolysis indicated that $T$. gondii infection might also result in dysregulation of those enzymes in humans, thus promoting a negative influence on the quality of male sperm. Normally, the energy production efficiency of oxidative phosphorylation is much higher than that of glycolysis, but glycolytic pathways have their particular importance in sperm energy sources. Mukai \& Okuno [24] noticed that when the oxidative phosphorylation was blocked by rotenone of mitochondrial respiratory chain inhibitors, the sperm keeps moving. Therefore, glycolysis is not only an important source of energy for sperm but also plays a role in sperm capacitation [25] and acrosome reaction [26, 27].

\section{Mitochondrial damage and apoptosis}

Spermatogenesis associated 18 (Spata18) is a key regulator of mitochondrial quality that mediates repair or degradation of unhealthy mitochondria [28]. There is no pathway for Spata18, but previous research has shown that it is a monitor of cell differentiation process, which is involved in the maturation of spermatids into spermatozoa [29].

In our study, the expression of Tnfsf 10 gene was upregulated to 2.89-fold in the pathway of cytokine-cytokine receptor interaction, apoptosis and natural killer cell 


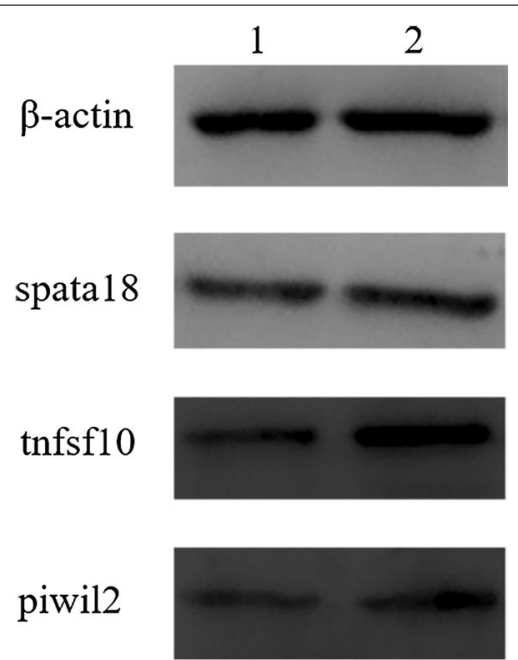

Fig. 6 Results of Western blot compared with RNA-seq. Lane 1: control group; Lane 2: infection group; from top to bottom, represent the $\beta$-actin internal reference, spata18, tnfsf10 and piwil2 protein

mediated cytotoxicity. Tnfsf 10 (Trail) is a member of the tumor necrosis factor (TNF) superfamily, and is an important signal molecule to maintain the stability of germ cells and the functional spermatogenesis in testis [30]. Apoptosis, or programmed cell death (PCD), is a biological process controlled by genes and plays a vital role in maintaining the morphology of normal tissues and organs. So far, the mitochondrial pathway is considered to be the classical pathway of apoptotic signal pathways. Mitochondria control the life and death of cells in aerobic environments, which is the main place of ATP production, and the major regulatory site of cell apoptosis. Mitochondrial permeability transition pores (MPTP) exist in the inner and outer membranes of mitochondria, and the permeability transition plays a vital role in cell apoptosis [31]. The pathway of cytokinecytokine receptor interaction shows $\operatorname{Tnfsf} 10$ as a cytokine and interacts with the cytokine receptor Tnfsf10b. In the apoptosis pathway, $\operatorname{Tnfs} f 10 b$ (2.3-fold upregulation) as a death receptor, interacts with $\operatorname{Tnfs} f 10$ causing production of the death inducing signaling complex (DISC), which initiates the caspaseprotease family (aspartate-specific cysteine proteases) and activates apoptosis through DNA fragmentation, low synthesis of ploy, and destruction of nuclear membrane integrity [32]. At the same time, the translocation and permeabilization of mitochondrial membrane could induce apoptosis through Bax/Bak [33]. MPTP opening resulting from exogenous injury factors (such as $\mathrm{Ca}^{2+}$ overload) would lead to necrosis and apoptosis of cells. Some scholars have found that the synergism of melittin with Trail could increase the number of apoptosis in hepatoma cell through activating $\mathrm{Ca}^{2+}$ / calmodulin-dependent protein kinase [34]. This is consistent with the finding of Chen et al. [35] who stated that the $\mathrm{Ca}^{2+}$ dependent calpain and/or $\mathrm{Ca}^{2+}$ independent cathepsins participate in apoptosis-like PCD and necrosis-like PCD. Trail gene-deficient (Trail2/2) mice were significantly reduced by $54 \%$ compared to the wild type mice, which explains the negative effects on sperm maturation in the reproductive system [30]. A high concentration of soluble Tnfsf 10 was detected in the seminal plasma, which revealed a variable expression of Trail receptors in the sperm cellular fraction among different participants [36]. Those results suggest that Tnfsf10 may play an important role in sperm maturation.

The cytotoxicity of natural killer (NK) cells is motivated by the activating cell receptors. It can switch on the cascade reaction of downstream signal transduction. In our study, the Src family kinase (Fcgr4) was related to the cytotoxic pathway which is mediated by NK cells. The Fcgr4 also could active the mitogen activated protein kinase (MAPK) pathway, which could produce the cytotoxicity and secret proinflammatory cytokines (such as IFN- $\gamma$, TNF- $\alpha$ and GMCS). The upregulation of piwi and $\operatorname{Itg} b 2$ genes mediates the target cell apoptosis by $\operatorname{Tnfsf10}$, which is caused by perforin and granzyme. The Gzmb (Granzyme B) gene is responsible for aspartate-specific cysteine proteases (DNA fragmentation, low synthesis of ploy and destruction of nuclear membrane integrity) which cause apoptosis.

From these pathways, we consider that $\operatorname{Tnfsf10}$ is directly or indirectly connected with the male reproductive system. Chronic infection of $T$. gondii gives rise to dysregulation genes in these pathways, which in turn have a negative consequence on the integrity and motility of sperm. At the stage where spermatids mature into spermatozoa, mitochondria formed the mitochondrial sheath by gathering around the tail and wrapping around the shaft spirally. Finally, it can provide the energy for rotational motion of the tail in the way of making full use of energy in plasma drops. The fertility was influenced by various channels to create the apoptosis of germ cells.

\section{Testis-specific genes in the epididymis}

Our data analysis revealed that many DEGs were upregulated in the epididymis; however, previous studies have shown that they are testicular-specific genes, such as Piwil2 and RGS22 (regulator of G-protein signaling 22) genes. Piwil2 is a member of the Argonaute family and PIWI (the P-element-induced wimpy testis) subfamily. PIWI family proteins are only expressed in animal gonad tissues and have tissue specificity, these are closely related to the maintenance of germ stem cells and spermatogenesis [37]. The Piwil2 gene, expressed in tumor stem cells and germ cells, plays an 
Table 7 The testis-specific gene was highly expressed in the epididymis

\begin{tabular}{|c|c|c|c|}
\hline Symbol & $\log 2(F C)$ & Tissue specificity & Function \\
\hline Piwil2 & 1.1907 & $\begin{array}{l}\text { Expressed in adult testis, specifically in spermatocytes and in } \\
\text { spermatogonia }\end{array}$ & $\begin{array}{l}\text { Plays an essential role in meiotic differentiation of spermatocytes } \\
\text { and self-renewal of spermatogonial stem cells }\end{array}$ \\
\hline $\operatorname{Rgs} 22$ & 2.18187 & $\begin{array}{l}\text { Expressed in testis, including in Leydig cells and spermatogenic } \\
\text { cells from the spermatogonia to spermatid stages }\end{array}$ & Negative regulation of signal transduction \\
\hline Shcbp11 & 1.78449 & $\begin{array}{l}\text { Testis-specific. Expressed in pachytene spermatocytes and } \\
\text { elongating spermatids inside the seminiferous tubules }\end{array}$ & $\begin{array}{l}\text { Testis-specific spindle-associated factor that plays a role in } \\
\text { spermatogenesis }\end{array}$ \\
\hline Spz1 & 1.08852 & $\begin{array}{l}\text { Expressed specifically in the testis (Sertoli and Leydig cells) and } \\
\text { epididymis }\end{array}$ & $\begin{array}{l}\text { Play an important role in the regulation of cell proliferation and } \\
\text { differentiation during spermatogenesis }\end{array}$ \\
\hline Spata18 & 1.29567 & In testis, expressed primarily in spermatids & $\begin{array}{l}\text { Key regulator of mitochondrial quality that mediates the repair- } \\
\text { ing or degradation of unhealthy mitochondria in response to } \\
\text { mitochondrial damage }\end{array}$ \\
\hline
\end{tabular}

important role in the self-renewal of stem cells, embryo formation and transcriptional regulation [38]. Similarly, $\operatorname{Rgs} 22$ is a specific gene in the male testis, which can be expressed simultaneously in a variety of epithelial tumors. In testis, Rgs 22 protein is associated with spermatogenesis, which can be expressed in spermatogenic cells involved in the spermatogonia differentiation into sperm cells and Sertoli cells. Hu et al. [39] found that the expression of Rgs 22 was downregulated in patients with azoospermia. Proteins are located in spermatogenic cells and Leydig cells, which interact with the guanine-nucleotide-binding proteins [39]. Thus, we consider that $R g s 22$ may be related to the meiotic stage of spermatogenesis.

In summary, Piwil2 and Rgs22 genes are testis-specific genes, mainly expressed in spermatogenic cells and play a key role in the spermatogenesis process. Other genes that were identified (see Table 7) are testis-specific and highly expressed in the epididymis. One possible reason for the latter observation is the invasion of T. gondii, which contributes to the destruction of the blood-testis barrier of the testis, and disruption of the spermatogenesis homeostasis [40]. Furthermore, spermatogenic cells in the seminiferous tubules were disordered, resulting in the increase of testis-specific gene expression in the epididymis. However, the epididymis has its tissue-specific microenvironment [41, 42] which is different from that in the testis. The microenvironment in the epididymis is not appropriate to regulate the cells in the testis and therefore, the specific mechanism is unclear and needs further investigation.

\section{Conclusions}

We sequenced the reproductive system of male mice chronically infected with $T$. gondii, which provides a new direction for research into male sterility caused by Toxoplasma infection. This work provides valuable information and a comprehensive database for future studies of the interaction between $T$. gondii infection and the male reproductive system.

\section{Supplementary information}

Supplementary information accompanies this paper at https://doi. org/10.1186/s13071-019-3783-2.

Additional file 1: Text S1. Detailed methods of transcriptome sequencing, data analysis and verification.

Additional file 2: Figure S1. Effect of T. gondii infection on total sperm count.

Additional file 3: Figure S2. Identification of infection in experimental mice.

\section{Abbreviations}

PRU: Prugniaud; DEGs: differentially expressed genes; FDR: false discovery rate; FC: fold change; GO: Gene Ontology; AsAb: anti-sperm antibodies; RNA-seq: RNA sequencing; Gb: gigabases; FPKM: fragment per kilobase of exon model per million mapped reads; SAM: sequence alignment/map format; GTF: gene transfer format; UCSC: University of California Santa Cruz; FRP: horseradish peroxidase; DAB: diaminobenzidine; ECL: enhanced chemiluminescence; KEGG: Kyoto Encyclopedia of Genes and Genomes; MGl: mouse genome informatics; RIN: RNA integrity number; PV: parasitophorous vacuoles.

\section{Acknowledgements}

Not applicable.

\section{Authors' contributions}

YXZ contributed to the data analysis and the writing of the manuscript. XXZ contributed to the drafting of the manuscript. JAH and YSM contributed to the revising of the manuscript. $W Y H, G F L, Y P W$ and $X Z$ contributed to the data collection and the laboratory work. $Y X Z$ and $X X Z$ contributed to the animal experiment. ZGY and XML contributed to the conception of the idea and design. All authors read and approved the final manuscript.

\section{Funding}

This work was supported, in part, by grants from the National Key Research and Development Programme of China (2017YFD0501305), National Natural Science Foundation of China (31972707), Major Scientific Research Projects (Characteristic Innovation) of Guangdong Province (2017KTSCX018), the Key Research and Development Programme of Guangdong Province (2019B020218004), the Guangzhou Zoo Project (h2016141), the Natural Science Foundation of Guangdong Province (2019A1515011534, 2016A030313396), and Huizhou Science and Technology Projects (2015B040009001). 


\section{Availability of data and materials}

We have uploaded the transcriptome data to the Sequence Read Archive (SRA) database, submission: SUB5863608, accession ID: PRJNA552423

\section{Ethics approval and consent to participate}

This study was carried out in accordance with the principles of the Basel Declaration and recommendations of the People's Republic of China, the Animal Ethics Committee of South China Agricultural University. The protocol was approved by the South China Agricultural University Experimental Animal Welfare Ethics Committee (Approval No. SCXK 2013-0002)

\section{Consent for publication}

Not applicable.

\section{Competing interests}

The authors declare that they have no competing interests.

\begin{abstract}
Author details
${ }^{1}$ College of Veterinary Medicine, South China Agricultural University, Guangzhou 510642, Guangdong, People's Republic of China. ${ }^{2}$ Key Laboratory of Zoonosis Prevention and Control of Guangdong Province, Guangzhou 510642, People's Republic of China. ${ }^{3}$ College of plant, South China Agricultural University, Guangzhou 510642, Guangdong, People's Republic of China. ${ }^{4}$ College of Veterinary Medicine, University of Florida, 2015 SW 16th Avenue, Gainesville, FL 32610-0136, USA. ${ }^{5}$ Infectious Diseases, Department of Animal Medicine, Faculty of Veterinary Medicine, Zagazig University, Zagazig, Sharkia Province 44511, Egypt. ${ }^{6}$ IRTA, Centre for Research into Animal Health (CReSA-IRTA), Campus of Autonomous University of Barcelona, Bellaterra, 08193 Barcelona, Spain. ${ }^{7}$ College of Animal Science and Technology, Heilongjiang BaYi Agricultural University, Daqing 163319, People's Republic of China.
\end{abstract}

\section{Received: 21 March 2019 Accepted: 30 October 2019}

Published online: 08 November 2019

\section{References}

1. Jones JL, Dubey JP. Foodborne toxoplasmosis. Clin Infect Dis. 2012;55:845-51

2. Zhou P, Chen Z, Li HL, Zheng H, He S, Lin RQ, Zhu XQ. Toxoplasma gondii infection in humans in China. Parasites Vectors. 2011;4:165.

3. Guha R, Miley L, Aspiri M, Dhamija R. Congenital toxoplasmosis. Pediatr Neurol. 2017;70:81-2.

4. Barreto F, Hering F, Dall'Oglio MF, Martini FD, Campagnari JC, Srougi M. Testicular toxoplasmosis: a rare case of a testicular mass. Actas Urol Esp. 2008;32:666-8.

5. Suresh BP, Nagendra K, Navaz RS, Ravindranath HM. Congenital toxoplasmosis presenting as hypogonadotropic hypogonadism. Indian J Pediatr. 2007:74:577-9.

6. Bohring C, Skrzypek J, Krause W. Influence of antisperm antibodies on the acrosome reaction as determined by flow cytometry. Fertil Steril. 2001;76:275-80

7. Oktenli C, Doganci L, Ozgurtas T, Araz RE, Tanyuksel M, Musabak U, et al. Transient hypogonadotrophic hypogonadism in males with acute toxoplasmosis: suppressive effect of interleukin-1 beta on the secretion of GnRH. Hum Reprod. 2004;19:859-66.

8. Terpsidis KI, Papazahariadou MG, Taitzoglou IA, Papaioannou NG, Georgiadis MP, Theodoridis IT. Toxoplasma gondii: reproductive parameters in experimentally infected male rats. Exp Parasitol. 2009;121:238-41.

9. Abdoli A, Dalimi A, Movahedin M. Impaired reproductive function of male rats infected with Toxoplasma gondii. Andrologia. 2012;44(Suppl. 1):679-87.

10. Lockhart DJ, Winzeler EA. Genomics, gene expression and DNA arrays. Nature. 2000:405:827-36.

11. Wang Z, Gerstein $M$, Snyder M. RNA-Seq: a revolutionary tool for transcriptomics. Nat Rev Genet. 2009;10:57-63.

12. Lopes WD, Costa AJ, Souza FA, Rodrigues JD, Costa GH, Soares VE, et al. Semen variables of sheep (Ovis aries) experimentally infected with Toxoplasma gondii. Anim Reprod Sci. 2009;111:312-9.
13. Teixeira W, Tozato M, Pierucci JC, Vital GP, Cruz AC, Lopes W, et al. Investigation of Toxoplasma gondii in semen, testicle and epididymis tissues of primo-infected cats (Felis catus). Vet Parasitol. 2017;238:90-3.

14. Colosi HA, Jalali-Zadeh B, Colosi IA, Simon LM, Costache CA. Influence of Toxoplasma gondii infection on male fertility: a pilot study on immunocompetent human volunteers. Iran J Parasitol. 2015;10:402-9.

15. Martens S, Parvanova I, Zerrahn J, Griffiths G, Schell G, Reichmann G, et al. Disruption of Toxoplasma gondii parasitophorous vacuoles by the mouse p47-resistance GTPases. PLoS Pathog. 2005;1:e24.

16. Zhao Y, Ferguson DJ, Wilson DC, Howard JC, Sibley LD, Yap GS. Virulent Toxoplasma gondii evade immunity-related GTPase-mediated parasite vacuole disruption within primed macrophages. J Immunol. 2009;182:3775-81.

17. Lafuse WP, Brown D, Castle L, Zwilling BS. Cloning and characterization of a novel CDNA that is IFN-gamma-induced in mouse peritoneal macrophages and encodes a putative GTP-binding protein. J Leukoc Biol. 1995;57:477-83.

18. Liu XX, Zhang H, Shen XF, Liu FJ, Liu J, Wang WJ. Characteristics of testisspecific phosphoglycerate kinase 2 and its association with human sperm quality. Hum Reprod. 2016;31:273-9.

19. Danshina PV, Geyer CB, Dai Q, Goulding EH, Willis WD, Kitto GB, et al. Phosphoglycerate kinase 2 (PGK2) is essential for sperm function and male fertility in mice. Biol Reprod. 2010;82:136-45.

20. Nakamura N, Dai Q, Williams J, Goulding EH, Willis WD, Brown PR, et al. Disruption of a spermatogenic cell-specific mouse enolase 4 (eno4) gene causes sperm structural defects and male infertility. Biol Reprod. 2013;88:90.

21. Krisfalusi M, Miki K, Magyar PL, O’Brien DA. Multiple glycolytic enzymes are tightly bound to the fibrous sheath of mouse spermatozoa. Biol Reprod. 2006;75:270-8.

22. Goldberg E, Eddy EM, Duan C, Odet F. LDHC: the ultimate testis-specific gene. J Androl. 2010;31:86-94.

23. Odet F, Gabel SA, Williams J, London RE, Goldberg E, Eddy EM. Lactate dehydrogenase $C$ and energy metabolism in mouse sperm. Biol Reprod. 2011;85:556-64.

24. Mukai C, Okuno M. Glycolysis plays a major role for adenosine triphosphate supplementation in mouse sperm flagellar movement. Biol Reprod. 2004;71:540-7.

25. Ickowicz D, Finkelstein M, Breitbart H. Mechanism of sperm capacitation and the acrosome reaction: role of protein kinases. Asian J Androl. 2012;14:816-21.

26. Hung P, Miller MG, Meyers SA, VandeVoort CA. Sperm mitochondrial integrity is not required for hyperactivated motility, zona binding, or acrosome reaction in the rhesus macaque. Biol Reprod. 2008;79:367-75.

27. Fraser LR, Quinn PJ. A glycolytic product is obligatory for initiation of the sperm acrosome reaction and whiplash motility required for fertilization in the mouse. J Reprod Fertil. 1981;61:25-35.

28. Kitamura N, Nakamura Y, Miyamoto Y, Miyamoto T, Kabu K, Yoshida M et al. Mieap, a p53-inducible protein, controls mitochondrial quality by repairing or eliminating unhealthy mitochondria. PLOS ONE. 2011;6:e16060.

29. Bornstein C, Brosh R, Molchadsky A, Madar S, Kogan-Sakin I, Goldstein I, et al. SPATA18, a spermatogenesis-associated gene, is a novel transcriptional target of p53 and p63. Mol Cell Biol. 2011;31:1679-89.

30. Lin YC, Richburg JH. Characterization of the role of tumor necrosis factor apoptosis inducing ligand (TRAIL) in spermatogenesis through the evaluation of trail gene-deficient mice. PLOS ONE. 2014;9:e93926.

31. Polster BM, Fiskum G. Mitochondrial mechanisms of neural cell apoptosis. J Neurochem. 2004;90:1281-9.

32. Muzio M, Chinnaiyan AM, Kischkel FC, O'Rourke K, Shevchenko A, Ni J, et al. FLICE, a novel FADD-homologous ICE/CED-3-like protease, is recruited to the CD95 (Fas/APO-1) death-inducing signaling complex. Cell. 1996:85:817-27.

33. Nechushtan A, Smith CL, Lamensdorf I, Yoon SH, Youle RJ. Bax and Bak coalesce into novel mitochondria-associated clusters during apoptosis. J Cell Biol. 2001;153:1265-76.

34. Wang C, Chen T, Zhang N, Yang M, Li B, Lü X, et al. Melittin, a major component of bee venom, sensitizes human hepatocellular carcinoma cells to tumor necrosis factor-related apoptosis-inducing ligand (TRAIL)induced apoptosis by activating CaMKII-TAK1-JNK/p38 and inhibiting IkBa kinase-NFkB. J Biol Chem. 2009:284:3804-13. 
35. Chen J, Mehta JL, Haider N, Zhang X, Narula J, Li D. Role of caspases in Ox-LDL-induced apoptotic cascade in human coronary artery endothelial cells. Circ Res. 2004;94:370-6.

36. Zauli G, Celeghini C, Monasta L, Martinelli M, Luppi S, Gonelli A, et al. Soluble TRAIL is present at high concentrations in seminal plasma and promotes spermatozoa survival. Reproduction. 2014;148:191-8.

37. Kuramochi-Miyagawa S, Kimura T, ljiri TW, Isobe T, Asada N, Fujita Y, et al. Mili, a mammalian member of piwi family gene, is essential for spermatogenesis. Development. 2004:131:839-49.

38. Ling W, Zhigang H, Tian H, Bin Z, Xiaolin X, Hongxiu Z. HPV 16 infection up-regulates Piwil2, which affects cell proliferation and invasion in cervical cancer by regulating MMP-9 via the MAPK pathway. Eur J Gynaecol Oncol. 2015;36:647-54.

39. Hu Y, Xing J, Chen L, Guo X, Du Y, Zhao C, et al. RGS22, a novel testis-specific regulator of $\mathrm{G}$-protein signaling involved in human and mouse spermiogenesis along with GNA12/13 subunits. Biol Reprod. 2008;79:1021-9.
40. Yang R. Effect of Toxoplasma gondii infection on cytokines and spermatogenic cells in rats. Zhongguo Ji Sheng Chong Xue Yu Ji Sheng Chong Bing Za Zhi. 2011;29:274-8.

41. Dacheux JL, Belleannee C, Jones R, Labas V, Belghazi M, Guyonnet B, et al. Mammalian epididymal proteome. Mol Cell Endocrinol. 2009;306:45-50.

42. Gatti JL, Castella S, Dacheux F, Ecroyd H, Metayer S, Thimon V, et al. Post-testicular sperm environment and fertility. Anim Reprod Sci. 2004;82-83:321-39.

\section{Publisher's Note}

Springer Nature remains neutral with regard to jurisdictional claims in published maps and institutional affiliations.
Ready to submit your research? Choose BMC and benefit from:

- fast, convenient online submission

- thorough peer review by experienced researchers in your field

- rapid publication on acceptance

- support for research data, including large and complex data types

- gold Open Access which fosters wider collaboration and increased citations

- maximum visibility for your research: over $100 \mathrm{M}$ website views per year

At BMC, research is always in progress.

Learn more biomedcentral.com/submissions 